\title{
Training Scientific Research Thinking and Innovation Consciousness in Series of Professional Courses
}

\author{
Xiuzhen HU, Hasihua, Jun Lv, Changjiang Ding \\ College of Science, Inner Mongolia University of Technology \\ Hohhot, China 010051
}

\begin{abstract}
The graduates are confronted with insufficiency of sensitive scientific research thinking and innovation consciousness when they step into stage of doing researches and writing papers. This is also a primary constraint of scientific research innovation. In this article, we will introduce our revolutions on educational idea, content and method of teaching in series of professional courses. Our research shows that this reform in education is capable to effectively speed up graduates' paper work process and improves graduates' paper work quality. Development of graduates' innovation consciousness is a systematic program, which not only need education reformation in series of professional courses simultaneously but also require a perfect cooperation among these courses.
\end{abstract}

Keywords-professional course; educational reform; innovating consciousness; study and practice

\section{INTRODUCTION}

Introduction Innovation consciousness motivates people to create unprecedented objects or conceptions, according to development requirements of society and individual, and in the process of these creative activities, people reveal their intention, aspiration and imagination. It's a positive and productive pattern of expression in human conscious activities, an internal motivation and starting point of human creative activities and obviously, also a premise of creative thinking and creative power. The main characteristic of innovation consciousness is seeking the new consciousness and producing creative achievements. Innovation consciousness is the prerequisite and condition of creative thinking. On the other hand, creative thinking is the inevitable result of innovation consciousness. Innovation consciousness is necessary to creative talents, and it is the starting point of cultivating and developing creative talents.

Colleges and Universities offer specialized courses to introduce professional knowledge and expertise to cultivating objectives. The task of specialized courses is to enable students to master the professional necessary basic theory, professional knowledge and professional skills, to understand the development trends of cutting edge of the professional science and technology, and to foster students' capability of analyzing and solving practical problems among experts. The duration of the specialized courses is earlier than the paper work. In general, specialized courses started immediately after the start of school, and the number of specialized courses usually is no less than seven. Therefore, it is very advantageous to penetrate and cultivate the creative consciousness of graduates on specialized courses, and it is the reason why specialized courses are irreplaceable for other courses (such as public lessons) [1].

At present, graduates' poor innovation awareness seriously hinders their research work, and directly restricts results of their scientific research. Since little attention is paid to the educational concept of cultivating innovation spirit, innovation idea infusion didn't start from graduates entering college, and innovation concept didn't penetrate into the professional courses education. Students only begin to be aware of the importance of innovation consciousness when they enter research and paper work stage. Thus, in the paper and research work, innovation thinking and innovation results are affected. While, even if some teachers are aware of the essential of innovation cultivation, and make a reform in their curriculum, the effect of training innovation awareness is not obvious, because innovation awareness training is a systematic program that requires cooperation among a series of specialized courses to complete. This article primarily focuses on that the cultivation of graduate students' awareness of innovation is a systematic program, which should be started from the professional courses. As for specialized courses, it requires a number of cohesions, co-ordinations and consciously reforms on education and teaching content, teaching methods and performance evaluation methods, in order to guide graduates to be good at asking questions, enjoy thinking, and seeks problem settlements by consulting literatures and other problem-solving approaches. Ultimately, purpose of cultivating graduate students' scientific research thoughts and innovation consciousness will be achieved. Therefore, the cultivation of graduate students' scientific research thoughts and innovative thinking are the core of graduate education and also the key to strengthen graduate education.

\section{THE SPECIALIZED COURSE IS ESSENTIAL SEGMENT OF CULTIVATING INNOVATION CONSCIOUSNESS OF GRADUATE STUDENTS}

Graduate education is divided into two stages: basic knowledge learning and scientific research. In order to do a good job in research paper work, we must have a good innovation consciousness and scientific thinking ability, since innovation ability comes from innovation consciousness. The cultivation of innovative consciousness is an unconsciously influence process, therefore, cultivation of innovation 
consciousness on the basic knowledge learning stage is very important. Cultivation of graduates' innovative consciousness must be paid attention to, however, the problem is that should innovation consciousness be cultivated on public courses of basic knowledge learning stage or on specialized courses? The general course mainly popularizes and expands the basic knowledge, such as foreign languages and mathematics of graduate students. It aims to strengthen the quality education, and provide a useful tool for the following scientific research. The specialized course is important stage for a graduate student to transform from studying professional knowledge to carrying out scientific research and is also the basis of research paper work. Therefore, teaching of specialized courses is an important part for the instructor to cultivate graduate students' scientific thinking and innovation [2].

\section{ESTABLISHING INSTRUCTOR'S CONCEPT OF CULTIVATING GRADUATES' CREATIVE CONSCIOUSNESS}

Teachers are guide and inspiration of students. To cultivate students' innovative ability and awareness, teachers must set cultivating innovative talents as the goal, constantly update the concept of education, explore new teaching model, and impassion students' self-creation in process of learning activities. Therefore, teaching must be around key and difficult points of teaching materials, timely interspersed with cuttingedge subjects and practical research cases, and carefully design classroom teaching to inspire thinking, and stimulate students' thirst of knowledge [3].

We have studied some of the colleges' graduate professional courses teaching. Most of their classroom teachings are just a repeat of textbook, although teaching contents conform perfectly to the textbook, exam problems that are basically combination of textbook contents and exercises seriously obstruct enlightenment of scientific thinking and innovative ideas on professional course. The characteristics of teaching should be research-based learning. Teaching methods, teaching thinking, teaching purpose and effect of instructors should not be stereotyped, besides, instructors should leave room for graduate students to raise questions, so that students can be interested in searching answers.

And there are colleges that regard scientific research cases as part of specialized course. This course structure expands the amount of classroom information and has positive effect on cultivation of innovative consciousness.

But its deficiency is that it doesn't achieve cooperation and collaboration among specific courses, which lead to the cultivation of innovative consciousness is not continuous. After the end of a course, the emerging ambiguity sense of innovation is interrupted, since cultivating the idea of innovative consciousness in professional courses are not deep in mind of some teachers, and the coordination of cultivating consciousness of specialized courses is incomplete. Thereby, the cultivation of scientific research thinking and innovation consciousness of graduate students is seriously restrained.

It is very important to cultivate postgraduates' scientific research thinking and innovation consciousness in specialized courses. The cultivation of innovation consciousness is a systematic program which needs teachers and students to cooperate with each other, more professional courses to connect and cooperate with each other. Then, the purpose of cultivating graduate students' thinking and innovative awareness will be achieved by penetrating the scientific frontier information, guiding graduate students' awareness and interest in research, and teaching graduate students to find solutions of problems through searching for information and other ways.

\section{HOW TO CULTIVATE INNOVATION CONSCIOUSNESS OF GRADUATES ON SPECIALIZED COURSES}

On the undergraduate level, the teacher's teaching content, the student's learning content and the examination are generally based on the textbook, so the undergraduate stage of knowledge learning is completely confined to the textbook. Students themselves rarely deeply think about the course content, much less of Innovation thinking. Although scientific research and graduation design (thesis) and other practice are included on undergraduate stage, all of those are only specified actions that have exact answers and are under instruction of teacher. In other words, they are a series of rigid patterns. So, the severe lack of independent thinking and innovation awareness exists undergraduate's stage.

In the graduate stage, the essential difference between graduate students and undergraduates is literally the "research", if teachers' teaching methods are exactly the same as on undergraduate stage, which has aptotic contents and model, and set up examinations according to course content. The learning of graduates' professional will seriously hinder the training of graduates' scientific research thinking and cultivation of their innovative thinking as the same as the effect of undergraduates' courses. An important purpose of graduates' education is to cultivate graduate students' independent scientific research ability including finding, analyzing and solving problems. Obviously, these abilities come from scientific thinking and innovation consciousness, therefore, how can we cultivate the innovation consciousness of graduate students in professional course becomes an increasingly concerned challenge. In this article, we take a series of reforms and attempts on teaching content, teaching methods, curriculum assessment and other aspects to make professional courses play a better role on cultivating scientific thinking and innovative consciousness [45].

\section{A. Integration of scientific research and teaching}

Under the premise of guaranteeing the systematism of disciplinary knowledge as far as possible, the arrangement of the teaching content will highlight the inquiry study and incorporate modern scientific research into teaching. Due to the differences in the professional quality of students, the basic concepts and principles of professional courses can't be neglected. However, in order to cultivate the scientific thinking and innovation consciousness of graduate students in the special course, the teaching content of course must be updated timely, extended on depth and width and added with advanced topics. For instance, on the specialized course "Modern Molecular Biology", when we explained generic materials, we added the topic of generic sequence prediction including the 
prediction of gene coding region starting site, researches of generic sequence analysis and prediction, researches of human generic splicing site, discussions of generic sequences and codon usage and so on. When we introduced the content of protein structure, we added topics of researched and predictions based on secondary structure, super-secondary structure, tertiary structure and structural domain of protein sequences, so that students would initially understand the research progress of special structures of protein. On the specialized course "theoretical biophysics", we interspersed with some biological mathematical algorithms and some problem-solving methods to make students comprehend correlations among mathematics, physics, computer and life science, and coexistence of differences of disciplines and cross-disciplines. Through extensive collection of relevant information at home and abroad, we enriched latest scientific research results of every subjects into the teaching contents, so that strong interest of graduate students would be generated and further some research questions would be come up with. This will contribute a lot to research paper work of graduate students. Therefore, how to properly manage the relationship between the classic content and the latest progress becomes an important part of the curriculum reform. What's more, discussion of how to add subjects and what contents should be added will be important part of the reform.

\section{B. Applicate modern teaching method to class teaching education}

Although some teachers of the professional course use of multimedia teaching, most of time they just repeat textbook contents. The situation that the instructor looking at the PPT, reads the concept of lectures contents to students is common. This situation greatly wasted the imagination of graduate students, and is never possible to cultivate graduates' innovation thinking. It is one of the direction of teaching reform to treat providing a good teaching environment as an integral part of cultivating innovation consciousness and ability. For the purpose of strengthening teaching effect, the PPT lecture that begin with manipulating picture, typeface, background, illustrations, shape, color, computing software and many other aspects, highlight the focus, and virialize abstract difficult contents, should be made for all contents of the classroom teaching. For instance, when we introduced the spatial structure of the protein, we inserted the whole process, form protein sequences forming secondary structure and supersecondary structure, then curling into a tertiary structure to equipment of four-stage structure made by FLASH. Consequently, students would form a basic impression of protein spatial structure formation in their mind, thus, this process would become easily for students to understand and memory. Besides, the biggest advantage of multimedia teaching is that it has ability to contain the amount of information of the teaching content. It is also beneficial a lot to add advanced topics to lessons. In addition, the network teaching is also an important means to ensure the quality and efficiency of teaching. The after- class network contact (such as, discussing professional issues and academic issues on QQ chat) is also very important, especially on online Q \& A. For example, if discussion class is in the evening of every Sunday, instructors will meet their students on the QQ group on Sunday night, and solve professional problems by a pleasant chat.

\section{The reform of the teaching method is a key}

The teacher, as mentor and participant, guides and encourages students to become the master and explorer of the study, provides students opportunity and stage to think, explore and create, inspires students' creative vitality, and makes students enjoy the results of their own thinking. As on the "Biology Mathematics" course, we will leave the relevant topics of calculation to the students, and one week after the designated student will report their research results about predecessors of the algorithm, personal views, and responds to questions raised by classmates and teachers. Teachers should not only concentrate their efforts on the "teaching", but should also pay more attention to the importance of inspiration, guided teaching, and applicate them into the teaching activities. Teaching process should focus on clarifying the origin background and concept of the problem, analyzing ideas, studying methods, the latest research progress and relevant research hotspots. Besides, during this process we also should guide students to advanced technology area of subjects and absorb new ideas, new methods, new technologies, new progress and problems to be solved into the graduates' education. Students should be guided actively think and discuss while listen to the teacher's explanation, so that students will transform from passive listeners into active explorers. We delicate to "guide and exploration", to teach students "how to fish", to enlighten students' thinking, and to train students' ability.

\section{The performance evaluation method reform}

Through performance evaluation, not only the purpose of examining study effect should be achieved, but also the purpose of intriguing exploration and thinking interest of graduate students need to be reached. The quality of students participating in class discussions should be regarded as an important part of the regular grades. The old opinion that evaluate study quality according to mastery condition of knowledge should be turned to focus on assessing students' ability of knowledge application and innovation, and students' comprehensive quality. In addition, literature review, report, oral defense, and discussion should become an important part of assessment. For instance, instructor can offer students several hotspots projects. Then students will choose the project that they are interested in most to do literature search, relevant materials overview, write report in accordance with the standard format and make PPT presentation. Finally, students will be asked to do presentation on the class and answer questions raised by the instructor and classmates. This whole process not only will improve the ability of self-learning, ability of accessing to information and information application, and ability of writing and oral expression of students, but also cultivate the scientific quality and innovation ability of students Therefore, the bad status that students' performance is totally decided by paper examinations will be significantly improved. 


\section{E. Coordination and cooperation among professional course}

It is difficult to achieve the purpose of cultivating graduates' scientific research thinking and innovation consciousness by a single specialized course. Coordination and cooperation among each professional course are necessary. Each professional course has its independence, at the same time, the combination of professional courses constitutes an organic whole, which builds a solid foundation for the professional research papers work [6]. Professional courses that we offered to cultivate graduates' innovation awareness in bioinformatics area are: "modern molecular biology", "theoretical biophysics", "bioinformatics", "VB language application", "biological mathematics "and" advanced quantum mechanics "and so on. These courses are adjusted on the teaching contents, to avoid the repetitive contents between different classes. We delete some of the classic, simple contents that even secondary school textbooks include, and relevant contents between different classes, and insert the frontier researches of bioinformatics. For example, to solve our questions in "modern molecular biology" students will need to download data using database usage method in "bioinformatics", to give algorithm according to mathematic model in "biological mathematics", to apply validation and estimation methods introduced by "Theoretical biophysics" to the prediction and to use coding in "VB language application" to do calculations. Through doing the project independently, courses are linked together. Thus, students will fully realize the importance and indispensable of each course, and basically experience the whole procedure of research.

\section{CONCLUSION}

In general, it does have some effect to implement teaching reform in the series of specialized courses to cultivate students' innovative consciousness of graduate students. Graduate students' sensitivity to research, application of knowledge, ability of searching for literature and writing greatly improved. The achievement of our job is reflected from graduates' performance on research paper work. Their paper research process is expedited distinctly, therefore, they can get some research achievements at the graduation. In recent years, the paper of graduate students reached the forefront of international standard. There are some papers published and collected by SCI, EI, and win the outstanding thesis award as well.

\section{ACKNOWLEDGMENT}

This work was supported by Education Department postgraduate education reform project of the Inner Mongolia of China (YJG20151012808).

\section{REFERENCES}

[1] H. HongXiang, X. Qingnian, G. Yunshen, "Lacking expression of postgraduate innovation power in our country", Academic Degrees \& Graduate Education,2005,vol. 9, pp. 32-36 (In Chinese).

[2] D. Yinghong, " Postgraduate course teaching methods to explore Based on scientific research and innovation ability training", Education teaching forum,2016, vol. 32, pp.163-164 (In Chinese).

[3] C. Jinyang, "Mentor role in discussing teaching of postgraduate professional courses", Higher education BBS,2010, vol. 6, pp. 103 107(In Chinese).

[4] Y. Rong, M. Min, G. Lan, W. Haijun, "Analysis on the Cultivation of Scientific Research Ability for College Postgraduates under New Situation", Education teaching forum,2017, vol. 11, pp. 244-245 (In Chinese ).

[5] L. Xican, D. Li, C. Kanglin, Z. Shuang, "Graduate students in our country sustainable innovation ability investigation and analysis of influencing factors ",Journal of Agricultural University of Hebei, 2017,vol. 19,pp.34-42 (In Chinese ).

[6] Z. Yuhua, X. Qingzhong, "Graduate curriculum education reform based on the course of learning and scientific research training integrate", Guangdong Chemical Industry, 2017,vol.44, pp.152-153. 